\title{
Human DNA Ligase III Recognizes DNA Ends by Dynamic Switching Between Two DNA Bound States ${ }^{\dagger}$
}

\author{
Elizabeth Cotner-Gohara ${ }^{1,6}$, In-Kwon Kim ${ }^{1,6}$, Michal Hammel ${ }^{2}$, John A. Tainer ${ }^{3,4}$, Alan E. \\ Tomkinson $^{5}$, and Tom Ellenberger ${ }^{1, *}$ \\ ${ }^{1}$ Department of Biochemistry and Molecular Biophysics, Washington University School of \\ Medicine, St. Louis, MO 63110, USA \\ 2 Physical Biosciences Division, Lawrence Berkeley National Laboratory, Berkeley, CA 94720, \\ USA \\ ${ }^{3}$ Life Sciences Division, Lawrence Berkeley National Laboratory, Berkeley, CA 94720, USA \\ ${ }^{4}$ Department of Molecular Biology and The Skaggs Institute for Chemical Biology, The Scripps \\ Research Institute, La Jolla, CA 92037, USA
}

${ }^{5}$ University of Maryland School of Medicine, Baltimore, MD

\begin{abstract}
Human DNA ligase III has essential functions in nuclear and mitochondrial DNA replication and repair and contains a PARP-like zinc finger $(\mathrm{ZnF})$ that increases DNA nick-joining and intermolecular DNA ligation. Yet, the bases for ligase III specificity and structural variation among human ligases are not understood. Here combined crystal structure and small angle x-ray scattering results reveal dynamic switching between two nick-binding components of ligase III: the ZnF-DNA binding domain (DBD) form a crescent-shaped surface used for DNA end recognition which switches to a ring formed by the nucleotidyl transferase (NTase) -OB-fold (OBD) domains for catalysis. Structural and mutational analyses indicate that high flexibility and distinct DNA binding domain features in ligase III assist both nick-sensing and the transition from nick-sensing by the $\mathrm{ZnF}$ to nick-joining by the catalytic core. The collective results support a "jackknife model" whereby the ZnF loads ligase III onto nicked DNA and conformational changes deliver DNA into the active site. This work has implications for the biological specificity of DNA ligases and functions of PARP-like zinc fingers.
\end{abstract}

DNA ligase III is a vertebrate-specific protein functioning in DNA replication and repair pathways, including nucleotide excision repair, base excision repair, and single-strand break repair, plus mitochondrial replication and repair (1). DNA ligase III is furthermore

\footnotetext{
${ }^{\dagger}$ This work was supported in part by grants from the National Institutes of Health (NIH) including (5R01 GM052504; TE), and The Structural Cell Biology of DNA Repair Program (P01 CA92584; AET, TE, JAT). Funding for the SIBYLS beamline was provided in part by the Offices of Science and Biological and Environmental Research, U.S. Department of Energy, under Contract DEAC02-05CH11231. This work includes research conducted at the Northeastern Collaborative Access Team beamlines of the Advanced Photon Source, supported by award RR-15301 from the National Center for Research Resources at the National Institute of Health. Use of the Advanced Photon Source is supported by the U.S. Department of Energy, Office of Basic Energy Sciences, under Contract No. DE-AC02-06CH11357.

*Correspondence: (314) 362-0287 (phone); (314) 362-4432 (fax); tome@ biochem.wustl.edu.

${ }^{6}$ These authors contributed equally to this work

Coordinates have been deposited with the Protein Data Bank as entry 3L2P.

Supporting Information Available

We provide additional figures and experimental procedures in the supporting information. This material is available free of charge via the Internet at: http://pubs.acs.org.
} 
implicated in the repair of DNA double-strand breaks when nonhomologous end joining (NHEJ) activity is compromised (2). Upregulated ligase III expression in chronic myeloid leukemia cells, with concomitant decreases in the expression of the NHEJ proteins DNA ligase IV and Artemis, may promote cell survival and disease progression, raising the possibility of selectively inhibiting ligase III as a cancer treatment (3). Besides repairing nuclear DNA, ligase III is the only mitochondrial DNA ligase where it functions in DNA repair and replication.

Three DNA ligase III isoforms are generated by alternative mRNA splicing and translation initiation, and expression of one or more of these is essential for the viability of mammalian cells and animals (4). The LigIII $\alpha$ isoform interacts with XRCC1 through a C-terminal BRCA1-related C-terminal (BRCT) domain, and this protein complex functions in a variety of DNA repair pathways, most prominently in the repair of DNA single-strand breaks $(5,6)$. LigIII $\beta$ lacks the C-terminal BRCT domain $(6,7)$, and is expressed only in the male germ line where it presumably repairs DNA strand breaks during meiotic recombination $(7,8)$. The mitochondrial DNA ligase III (mtLigIII) isoform has an N-terminal mitochondrial localization sequence besides the C-terminal BRCT interaction domain. However, XRCC1 is absent from mitochondria and mtLigIII appears to function alone in mitochondrial DNA maintenance $(9,10)$.

Besides LigIII, two other DNA ligases are expressed in mammalian cells. DNA ligase I (LigI) is an essential enzyme that repairs Okazaki fragments during DNA replication and also functions in long patch base excision repair. DNA ligase IV (LigIV) has specialized functions in the repair of DNA double-strand breaks by the NHEJ pathway, and in the rearrangement of immunoglobulin genes $(1,11)$. All three mammalian DNA ligases contain a homologous catalytic core, consisting of two domains that are structurally conserved in prokaryotic DNA ligases and other members of a superfamily of nucleotidyl transferases that includes mRNA-capping enzymes and RNA ligases (12). Additional N- and C-terminal regions flanking the catalytic core of mammalian DNA ligases provide other functions, including interactions with other proteins that dictate the subcellular localization of each enzyme. The nucleotidyl transferase (NTase) and OB-fold (OBD) domains comprise the catalytic core of DNA ligases that harbors essential residues participating in a three-step DNA end joining reaction (1). A third, noncatalytic domain located immediately $\mathrm{N}$-terminal to the catalytic core of all three mammalian DNA ligases (13) extends the DNA interaction surface of these enzymes. This DNA binding domain (DBD) is essential for DNA recognition and nick joining functions of human LigI (14) and LigIII (15). A crystal structure of LigI bound to a nicked DNA revealed that the DBD and the adjoining NTase and OBD domains form a compact, ring-shaped structure that sequesters the ends of the nicked strand in the active site (14). At present, it is unknown if this protein architecture is conserved in the other mammalian DNA ligases and how structural modifications specific to each enzyme may contribute to their different biological functions.

In particular, the LigIII polypeptides are distinguished from the other human DNA ligases by the presence of an $\mathrm{N}$-terminal zinc finger $(\mathrm{ZnF})$ domain that binds cooperatively in conjunction with the adjacent DBD domain to nicks and gaps in the backbone of duplex DNA (15). This DNA nick-sensing by the ZnF evidently contributes to substrate selection and increases the catalytic efficiency of nick-joining by DNA ligase III (15-18).

Furthermore, the $\mathrm{ZnF}$ has a profound effect on stimulating the intermolecular ligation of two DNAs (15), an activity likely relevant to the involvement of LigIII $\alpha / \mathrm{XRCC1}$ in the back-up pathway of nonhomologous end joining by ligase III (2). The DNA ligase III ZnF is structurally related to the two N-terminal zinc-finger domains of poly(ADP-ribose) polymerase (16). Although a study of the LigIII ZnF domain by NMR identified residues in a $\beta$-hairpin motif that are strongly perturbed by the addition of DNA (17), the molecular 
mechanisms by which DNA nick-sensing and catalytic activity are enhanced by the $\mathrm{ZnF}$ of LigIII are unknown.

To characterize the DNA interaction and structure of human ligase III, we combined x-ray crystal structural analysis with small angle $x$-ray scattering (SAXS) to analyze solution architectures and flexibility. These experiments suggest how DNA ligase III interactions and conformational changes contribute to DNA substrate selection and end joining activities. This multi-domain enzyme has a dynamic shape permitting alternative ensembles of domains to engage the DNA in competing configurations. Conformational switching can assist in loading DNA ligase III onto nicked DNA and promoting the juxtaposition of two DNA molecules in the active site for ligation of two DNAs.

\section{Experimental Procedures}

\section{Protein purification}

LigIII $\beta$ and $\Delta$ ZnF-LigIII were purified as described previously (Cotner-Gohara et al., 2008), and purified protein was concentrated to $30-40 \mathrm{mg} / \mathrm{ml}$ and stored at $-80^{\circ} \mathrm{C}$.

Selenomethionine labeled $\Delta$ ZnF-LigIII protein was expressed in BL21(DE3) using amino acids to suppress methionine biosynthesis, as described (19), and was purified by the same protocol as native protein. $\mathrm{LigIII}_{755}$ (residues 1-755) and $\Delta \mathrm{ZnF}_{755}$ (residues 170-755) were cloned into pET28a, and purified using same protocol as LigIII $\beta$ and $\Delta \mathrm{ZnF-LigIII,}$ respectively.

\section{Nicked DNA Substrate Preparation}

The DNA strands were synthesized on an Applied Biosystems 394 DNA/RNA Synthesizer and were desalted using a SepPak cartridge (Waters, Inc). The nicked DNA substrate was formed by annealing equimolar amounts of the three DNA strands: 5'CGGGATGCGTddC (upstream; ddC is 2', 3'-dideoxycytidine monophosphate), 5' $\mathrm{PO}_{4}$-GTCGGACTGGC (downstream), 5'GCCAGTCCGACGACGCATCCCG (template) in 5 mM MES pH 6.5 and $20 \mathrm{mM} \mathrm{NaCl}$.

\section{Crystallization}

A LigIII-DNA complex was formed by incubating $0.6 \mathrm{mM}$ nicked DNA substrate, $0.6 \mathrm{mM}$ $\triangle \mathrm{ZnF}$-LigIII $\beta, 10 \mathrm{mM}$ ATP and $100 \mathrm{mM} \mathrm{MgCl}$. The ligase-DNA complex was mixed with an equal volume of well solution (1.8 $\mathrm{M}$ ammonium sulfate, $0.1 \mathrm{M}$ sodium acetate $\mathrm{pH}$ 5.6). Crystals $\left(\mathrm{P} 4{ }_{1} 2{ }_{1} 2, \mathrm{a}=130.1 \AA, \mathrm{b}=130.1 \AA, \mathrm{c}=150.4 \AA\right.$ ) grew at $22^{\circ} \mathrm{C}$ by hanging drop vapor diffusion. Prior to flash-cooling in liquid nitrogen, crystals were washed in well solution and transferred to a cryoprotectant solution containing $1.8 \mathrm{M}$ ammonium sulfate, $0.2 \mathrm{M}$ sodium acetate $\mathrm{pH}$ 5.6, and 25\% glycerol. Crystals diffracted beyond $3.5 \AA$ using synchrotron radiation, and there is one LigIII $\beta \triangle \mathrm{ZnF}$ - DNA complex per asymmetric unit.

\section{X-ray Data Collection}

$\mathrm{X}$-ray diffraction data extending to $3.0 \AA$ resolution were collected from frozen crystals at the NE-CAT beamline at the Advanced Photon Source, Argonne, Illinois and at the MBC beamline at the Advanced Light Source, Berkeley, California. Data from two multiwavelength anomalous dispersion experiments and one native experiment were used. X-ray data were processed using HKL2000 (20) or d*trek then scaled using Scalepack $(20,21)$. Nineteen of twenty-one SeMet sites were located by automated Patterson searches using SOLVE (22). Heavy-atom parameters were refined and experimental phases were calculated in SHARP using the native dataset in combination with the MAD datasets (23). Experimentally phased maps had a well-defined solvent boundary and obvious electron density for both protein and nucleic acid. Phase improvement and density modification in 
SOLOMON in SHARP greatly enhanced the interpretability of the electron density. The binding register of the DNA with respect to the protein was determined using the clearly visible nick in the DNA backbone, and purines were distinguishable from pyrimidines. The SeMet sites, bulky amino acid side chains, and comparison to the DNA ligase I structure (14) helped define the amino acid register. The crystallographic model was constructed using COOT (24), with refinement in REFMAC (25). TLS parameters were refined using REFMAC, with the DBD, NTase and OBD domains and DNA treated as separate domains. Figures were generated using PYMOL (www.pymol.org), and molecular surface electrostatics were calculated with APBS (26). Crystallographic data statistics are shown in Table 1.

\section{Small Angle X-ray Scattering}

LigIII was adenylated with $5 \mathrm{mM} \mathrm{MgCl} 2$ and $1 \mathrm{mM} \mathrm{ATP} \mathrm{for} 1 \mathrm{hr}$ at $4^{\circ} \mathrm{C}$, and the reaction was quenched by adding $10 \mathrm{mM}$ EDTA. LigIII was dialyzed with a buffer containing 50 $\mathrm{mM}$ Tris- $\mathrm{HCl} \mathrm{pH}$ 7.5, $10 \%$ glycerol, $2 \mathrm{mM}$ DTT and $250 \mathrm{mM} \mathrm{NaCl}$. For protein-DNA complexes, 20-mer nicked DNA substrate (3'-OH nick for ZnF-lacking LigIII and 3'-ddC nick for ZnF-containing LigIII) was mixed with LigIII (protein : DNA $=1: 1.3$ ), and all protein-DNA complexes were purified by gel-filtration. However, comparison of purified and unpurified mixtures of LigIII $\beta$ and DNA in different molar ratios (from 1:0.8 to 1:1.2) gave comparable, although not identical results. LigIII $\beta$ binds tightly to DNA in a buffer with $50 \mathrm{mM}$ Tris- $\mathrm{HCl} \mathrm{pH} 7.5,10 \%$ glycerol, $2 \mathrm{mM}$ DTT and $250 \mathrm{mM} \mathrm{NaCl}$, while $\Delta \mathrm{ZnF}$ shows salt-dependent DNA-binding affinity on gel-filtration, which is consistent with the optimum near $100 \mathrm{mM} \mathrm{NaCl}$ for nick-joining and DNA-binding activities of $\triangle \mathrm{ZnF}(15,16)$. Thus, LigIII/ $/ \mathrm{LigIII}_{755}$-DNA complexes were purified at $250 \mathrm{mM} \mathrm{NaCl}$ to protect from aggregation, whereas $\Delta \mathrm{ZnF} / \Delta \mathrm{ZnF}_{755}$-DNA complexes were purified at $100 \mathrm{mM} \mathrm{NaCl}$.

SAXS data were collected at the ALS beamline 12.3.1 LBNL Berkeley, California (27). Incident $\mathrm{X}$-rays were tuned to a wavelength of $\lambda=1.0-1.5 \AA$ at a sample-to-detector distance of $1.5 \mathrm{~m}$, resulting in scattering vectors (q) ranging from $0.007 \AA^{-1}$ to $0.31 \AA^{-1}$. The scattering vector is defined as $q=4 \pi \sin \theta / \lambda$, where $2 \theta$ is the scattering angle. All experiments were performed at $20^{\circ} \mathrm{C}$ and data was processed as described (27). Briefly, the data were acquired at short and long time exposures $(0.5 \mathrm{~s}, 5 \mathrm{~s})$ then scaled and merged for calculations using the entire scattering spectrum. The experimental SAXS data were evaluated for aggregation by inspection of Guinier plots (28). The radius of gyration $\mathrm{R}_{\mathrm{g}}$ was derived by the Guinier approximation $I(q)=I(0) \exp \left(-q^{2} R_{g}{ }^{2} / 3\right)$ with the limits $q \mathrm{R}_{\mathrm{g}}<1.6$. The program GNOM (29) was used to compute the pair-distance distribution functions, $\mathrm{P}(\mathrm{r})$. This approach also provided the maximum dimension of the macromolecule, $\mathrm{D}_{\max }$. In our rigid body modeling strategy BILBOMD, molecular dynamics simulations were used to explore conformational space adopted by LigIII $\beta$ constructs. A Minimal Ensemble Search (MES) is used to identify the minimal set of conformers required to accurately fit the experimental data (30). For more details about data evaluation, see the Supplemental Data.

\section{Site-directed mutagenesis and mutants purification}

LigIII $\beta$ was mutated using the Quickchange site-directed mutagenesis kit (Stratagene), and mutant proteins were expressed in E. coli Rosetta cells. Cells were grown in LB medium containing ampicillin at $37^{\circ} \mathrm{C}$, and cultures were induced by $1 \mathrm{mM}$ isopropyl thiogalactoside at $16{ }^{\circ} \mathrm{C}$. After 16 hours of incubation, cells were harvested. Cells were resuspended in Buffer A (50 mM Tris- $\mathrm{HCl}$ pH 7.5, $150 \mathrm{mM} \mathrm{NaCl}, 0.2 \% \mathrm{NP}-40,5 \mathrm{mM} \beta$ mercaptoethanol, $1 \mathrm{mM}$ PMSF, $1 \mathrm{mM}$ benzamidine- $\mathrm{HCl}, 1 \mu \mathrm{g} / \mathrm{ml}$ aprotinin, $2 \mu \mathrm{g} / \mathrm{ml}$ leupeptin, $1 \mu \mathrm{g} / \mathrm{ml}$ pepstatin A, and $\mu \mathrm{g} / \mathrm{ml}$ chymostatin) and lysed by sonication. The lysate was clarified by centrifugation at $30,000 \mathrm{~g}$ for 1 hour at $4{ }^{\circ} \mathrm{C}$ and loaded onto a phosphocellulose column equilibrated with Buffer A. The fraction eluted with Buffer A with 
$1 \mathrm{M} \mathrm{NaCl}$ was pooled and loaded onto a $5 \mathrm{ml}$ HiTrap Nickel Chelating Column (GE Healthcare) equilibrated with Buffer B (50 mM Tris- $\mathrm{HCl} \mathrm{pH}$ 7.5, $250 \mathrm{mM} \mathrm{NaCl}, 5 \mathrm{mM} \beta$ mercaptoethanol, $1 \mathrm{mM}$ PMSF, and $1 \mathrm{mM}$ benzamidine-HCl). Following a wash with Buffer $\mathrm{B}$, the mutant proteins were eluted with stepwise with Buffer B plus $50 \mathrm{mM}$ and $500 \mathrm{mM}$ imidazole. Freshly purified protein was concentrated and used for the ligation assay.

\section{DNA End Joining Assays}

DNA ligation activities with nicked and blunt-ended DNA substrates were measured at 22

${ }^{\circ} \mathrm{C}$ as described previously (15). For ligation of an RNA:DNA heteroduplex containing a single strand nick, the downstream (15 mer) RNA oligonucleotide was 5'-labeled with polynucleotide kinase. RNA-containing substrates were reacted with full-length LigIII $\beta$ at 4 ${ }^{\circ} \mathrm{C}$ or $22{ }^{\circ} \mathrm{C}$, and DNA-containing substrates were reacted at $4{ }^{\circ} \mathrm{C}$ with different time points. Reactions were quenched by adding $10 \mathrm{mM}$ EDTA/formamide. The RNA oligonucleotide (15 mer), adenylated intermediate, and ligation product ( 28 mer) were separated by denaturing PAGE, and quantified by a phosphorimaging device (Fuji BAS1000).

\section{Results}

\section{Structural Organization of DNA Ligase III Complexed to DNA}

To define the molecular structure of LigIII and its DNA interactions, we crystallized the LigIII catalytic region comprising the DBD, NTase, and OBD domains ( $\triangle \mathrm{ZnF}$-LigIII $\beta$ protein) in complex with a 22-mer nicked DNA substrate (Figure 1). The enzyme was captured prior to step 2 of the ligation reaction with the AMP cofactor covalently bonded to Lys421 in the active site (Figure S1). The protein architecture and conformation of $\triangle \mathrm{ZnF}$ LigIII $\beta$ engaging nicked DNA resemble those of human LigI bound to nicked DNA (14), despite only $21 \%$ amino acid sequence identity. The three domains (DBD, NTase and OBD) completely encircle the DNA and sequester the $3^{\prime}-\mathrm{OH}$ and $5^{\prime}-\mathrm{PO}_{4}$ termini of the nicked DNA strand. Based upon this new structure, a clamp-like structure is a hallmark of eukaryotic DNA ligases bound to their DNA substrates $(14,31,32)$ that is mimicked by ligases from lower organisms $(14,31,32)$. The enclosed architecture of the enzyme-substrate complex may serve to orient the ends of two DNA strands for ligation. The LigIII NTase domain primarily engages the nicked DNA strand, whereas the OBD inserts into the minor groove of the DNA duplex opposite the nick, helping to secure the bound DNA within the active site of the NTase domain (Figure S2). A comparison of the crystal structures of human DNA ligase III and ligase I shows conserved residues within the NTase and OBD domains that interact with and stabilize the DNA in an underwound conformation, thereby exposing the ends of the nicked strand to the enzyme active site (Figure 1C) (14). The similarities between the pre-step 2 conformation of LigIII and the post-step 2 conformation of LigI indicate that no change in conformation is required during the step 2 adenylation of the DNA 5'-end.

This new structure of DNA ligase III shows that the DBD is a structurally conserved element of mammalian DNA ligases, despite only 14\% sequence identity between the DBDs of LigIII and LigI (Figure 2) (13). Not surprisingly, these enzymes have different DNA binding properties $(14,15,33,34)$ that may reflect an adaptation of LigIII to its additional $\mathrm{ZnF}$ domain. The DBD's $\alpha$-helical fold has a pseudo two-fold symmetry (Figure 1C) with each half consisting of a helix-hairpin-helix DNA binding motif and an extended loop that runs along the DNA backbone (Figure 1C). The DNA interaction surface of the DBD covers nearly one and one-half turns of the DNA double helix, contacting the DNA backbone and minor groove on the surface opposite to the nicked DNA strand. The connecting loops within each helix-hairpin-helix module are inserted into the minor groove where they interact with the edges of base pairs and the DNA phosphates. These interactions are 
compatible with the underwound structure of the DNA and widened minor groove in complex with LigIII.

The DBD also directly interacts with the NTase and OBD domains, resulting in a closed conformation of LigIII around the DNA nick (Figure 1A). In this conformation, the $\mathrm{ZnF}$ is precluded from accessing the nicked DNA strand, implying that the enzyme must adopt a different conformation to enable DNA nick-sensing by the $\mathrm{ZnF}$. However, the smaller buried surface area $\left(850 \AA^{2}\right)$ at the interface between the DBD and NTase domains of LigIII in comparison to LigI (1386 $\AA^{2}$; PDB ID: 1X9N) may provide greater flexibility to LigIII (Figure S3). This difference in buried surface area is attributed to a short loop in LigIII (residues Pro225-Asn235) that contacts the NTase domain and replaces a longer connecting loop of LigI (residues Asn336-Gly350). We suggest that the smaller, more hydrophilic interface may create a flexible hinge between the DBD and NTase domains of LigIII that facilitates a transition in protein conformation to the closed, catalytic conformation seen in the crystal structure from a nick-sensing conformation that enables the $\mathrm{ZnF}$ and $\mathrm{DBD}$ to bind cooperatively to DNA (15). Further evidence for the conformational flexibility of LigIII is seen in another loop (residues 376 to 383) that connects the DBD and NTase domains and is disordered in the crystal structure. The SAXS experiments described below provide additional evidence for the flexible structure of DNA ligase III.

\section{Interactions of Liglll with DNA and Nucleotide Substrates}

Although the structures of LigIII and LigI complexed with nicked DNA are similar, these enzymes have significantly different DNA binding activities. LigI binds to DNA with moderate affinity $\left(K_{\mathrm{DNA}}=0.4 \mu \mathrm{M}\right)$ but without specificity for nicked DNA. The LigI DBD accounts for most of this binding activity (14). LigIII binds to nicked DNA with comparable affinity, but relies on the adjacent $\mathrm{ZnF}$ domain to supplement the weaker binding affinity of its DBD ( $\left.\mathrm{K}_{\mathrm{DNA}}>20 \mu \mathrm{M} ;(15)\right)$. The DBD of LigIII is designed to function in concert with the $\mathrm{ZnF}$ domain, and this domain pair binds tightly and specifically to nicked DNA ( $\mathrm{K}_{\mathrm{DNA}}=$ $0.36 \pm 0.06 \mu \mathrm{M}$ ) in a cooperative manner in comparison to either domain in isolation (15). In the LigIII crystal structure, the DBD packs against the core NTase-OBD domains and presumably facilitates nick binding by the catalytic core. Thus, the DBD participates in two different modes of nick recognition by LigIII: the catalytic mode of DNA end joining seen in the crystal structure, and a nick-sensing mode requiring the enzyme to open so that the $\mathrm{ZnF}$ gains access to the DNA ends. The interaction of the LigIII DBD with DNA may coordinate the transition between different DNA binding modes that alternately engage the $\mathrm{ZnF}$ and catalytic core. Comparing the LigIII and LigI crystal structures, there are differences in the DNA contacts made by their DBDs. Differences in the amino acid sequences of the DNA contacting loops and their interactions with DNA likely contribute to the higher binding affinity of the LigI DBD.

LigI and LigIII also differ in their activities towards homopolymer substrates (33). Specifically, LigIII joins oligo(dT) molecules hybridized to poly(rA) whereas LigI does not (33). We previously proposed that the intimate contact of the LigI OBD with the minor groove of B-form DNA could explain discrimination against RNA-containing substrates (14) and this interaction is conserved in LigIII (Figure S4) We therefore experimentally tested the ability of LigIII to similarly discriminate against RNA-containing polymers of heterogeneous sequence. As predicted from the crystal structure, LigIII discriminates strongly against RNA-containing heteroduplexes, failing to ligate RNA-containing hereoduplexes under conditions that are permissive for DNA ligation (Figure S4B, left and center panels). Even under less stringent conditions, at higher temperature and with 25 -fold more ligase, LigIII ligates very little of the available RNA-containing substrate after 23 hours (less than 5\% ligated; Figure S4b, right panel). 


\section{A positively charged groove in the DBD supports $\mathrm{ZnF}$ activity}

A unique feature on the surface of the DBD from LigIII is a positively charged groove adjacent to the DNA binding surface (Figure 3A). This groove is located at the interface of two halves of the DBD between two parallel helices ( $\alpha 1$ and $\alpha 9$ ), but separated from the DNA binding surface identified in the crystal structure. In the LigI DBD, this groove is absent because the analogous flanking helices have bulky side chains that occupy the groove with uncharged residues (Figure 3A). LigIII helix $\alpha 9$ (residues 318-330) contains two basic residues (Lys323 and Arg327) that are primarily responsible for the positive charge of the groove whereas the hydrophobic side chains of helix $\alpha 1$ from the other half of the DBD (residues 287-301) participate in forming and stabilizing the groove through hydrophobic interactions with residues of helix $\alpha 9$. The two basic residues (Lys323 and Arg327) are unlikely to contact DNA directly as they located $8.0 \AA$ and $12.8 \AA$, respectively from the DNA interface (Figure 3B).

To test the importance of this groove in catalysis, a series of amino acid substitutions were introduced into the DBD of DNA ligase III. The LigIII mutants were assayed for a ZnFspecific activity, the blunt end joining of two DNAs, as well as the nick-joining activity that does not require the $\mathrm{ZnF}$. Substitution of either of the positively charged residues in the groove with a glutamate (K323E and R327E) significantly reduced blunt-end DNA ligation activity but had very little effect on DNA nick-joining activity (Figure 3C, D). We conclude that these mutations do not affect the core activities of LigIII but instead selectively block $\mathrm{ZnF}$ function. This effect was quantified by measuring the kinetics of ligation by the K323E and R327E mutants (Figure 3C, D). The K323E mutant showed an 87\% decrease in the initial velocity of blunt-end DNA ligation compared to wild-type LigIII. The R327E mutant is nearly devoid of blunt-end joining activity, mimicking a deletion of the $\mathrm{ZnF}$ ( $\triangle \mathrm{ZnF}$-LigIII protein). These results suggest an essential role for Arg327 in the function of the ZnF-DBD. In contrast, amino acid substitutions of other residues facing the DBD groove (R180E, A187E, and C324Y) had no significant effect on blunt-end joining (data not shown).

The substitution of Lys323 and Arg327 with glutamates eliminates the potential for two interhelical salt bridges between $\alpha 6$ and $\alpha 8$ involving the residue pairs Lys323-Glu265 and Arg327-Asp262, which could destabilize the local structure of DBD. However, the chargereversal mutations K323E/E265K and R327E/D262R did not restore efficient blunt-end DNA joining activity (Figure 3E). Our results indicate that two basic residues (Lys323 and Arg327) in the DBD of LigIII play critical roles in the ZnF-dependent intermolecular ligation. Given the location of these basic residues, it seems unlikely that they constitute a separate DNA binding site and we instead propose that the groove containing Lys323 and Arg327 contributes to interdomain interactions between the $\mathrm{ZnF}$ and DBD. This interaction could orient the $\mathrm{ZnF}$ to participate with the DBD in binding one DNA end while the catalytic core binds a second DNA end to promote blunt end joining (Figure 5).

\section{Conformational change of Liglll during DNA end joining}

To examine the conformation of DNA ligase III in the presence and absence of a DNA substrate, we performed small-angle X-ray scattering (SAXS) analyses with full-length LigIII $\beta$ and truncated proteins lacking the $\mathrm{ZnF}$ and ( $\mathrm{LigIII}_{755}$ and $\Delta \mathrm{ZnF}_{755}$; Figure 4$)$. SAXS provides accurate information about the size and shape of molecules sampled from a population of randomly oriented molecules in solution $(35,36)$. To simplify the analysis, the C-terminal region that is disordered in the crystal structure (residues 756-820) was also deleted, which resulted in a more compact overall structure but did not change the interactions with DNA (compare Figures 4 and S5). 
The pair-distribution functions $[\mathrm{P}(\mathrm{r})]$ calculated from the SAXS profiles of full-length and truncated versions of LigIII $\beta$ in the absence of DNA have an extended tail (Figure 4A and B) that is consistent with an elongated protein structure (36). When complexed with DNA, the $\mathrm{P}(\mathrm{r})$ functions are bell-shaped curves that are characteristic of compact globular proteins, particularly for LigIII lacking the $\mathrm{ZnF}\left(\Delta \mathrm{ZnF}_{755}\right.$-DNA; Figure $\left.4 \mathrm{~A}\right)$. These observations indicate that LigIII undergoes a large conformational transition that is triggered by binding to DNA, from the elongated unbound protein to a more compact structure in complex with DNA that presumably corresponds to the clamp structure observed in the crystals.

To further test the flexibility and conformational change of the $\Delta \mathrm{ZnF}_{755}$ protein in solution, we used a rigid body modeling procedure that incorporates molecular dynamics to survey conformational space (37). Ten thousand different conformations and their calculated SAXS profiles were generated for $\triangle \mathrm{ZnF}_{755}$ in the presence and absence of DNA, and then a Minimal Ensemble Search (MES) was used to identify the minimal number of conformations required to best fit the experimental data (see Experimental Procedures) (37). Combinations of three $\Delta \mathrm{ZnF}_{755}$ conformers with different conformations show better fit $\left(\chi^{2}\right.$ $=3.6)$ than the single best-fit model $\left(\chi^{2}=7.3\right)$, reflecting the flexibility of $\Delta \mathrm{ZnF}_{755}$ protein in the absence of DNA (Figure $4 \mathrm{C}$ and Table 2). For the $\Delta \mathrm{ZnF}_{755}$-DNA complex, a significantly better fit $\left(\chi^{2}=3.9\right)$ was obtained for mixtures of three conformers with closed and partially open conformations than for the crystal structure of $\triangle \mathrm{ZnF}-\mathrm{DNA}$ complex $\left(\chi^{2}=\right.$ 18.1) (Figure 4E). Thus, in the presence of nicked DNA, the LigIII protein exists in equilibrium between partially open and closed conformations.

\section{Flexible conformation of the ZnF during end joining}

What is the disposition of the $\mathrm{ZnF}$ domain in the closed, catalytically active conformation of LigIII $\beta$ bound to nicked DNA? The P(r) curve of LigIII protein containing the $\mathrm{ZnF}$ $\left(\right.$ LigIII $\left._{755}\right)$ is indicative of an elongated protein shape, even in the presence of DNA (Figure $4 \mathrm{~B})$. Given the dramatic sharpening of the $\mathrm{P}(\mathrm{r})$ peak for the $\Delta \mathrm{ZnF}_{755}$-DNA complex, and the elongated $\mathrm{P}(\mathrm{r})$ curve of the LigIII ${ }_{755}$-DNA complex with its significantly larger $\mathrm{D}_{\max }$ value $\left(\sim 180 \AA\right.$ vs. $\sim 125 \AA$ for $\Delta \mathrm{ZnF}_{755}$-DNA; Table 2$)$, it appears that the $\mathrm{ZnF}$ that does not pack against the DNA and/or other domains of ligase III but instead exists in an extended conformation both in the presence and absence of DNA.

To examine the potential flexibility of the $\mathrm{ZnF}$ domain, we again used molecular dynamics simulation to sample conformations of $\mathrm{LigII}_{755}$ in the presence and absence of DNA. An ensemble of three conformers of $\mathrm{LigIII}_{755}$ protein with different $\mathrm{ZnF}$ conformations improved the fit to the experimental $\mathrm{P}(\mathrm{r})$ curve $\left(\chi^{2}=3.9\right)$ in comparison to the single best-fit model $\left(\chi^{2}=6.1\right)$ (Figure $4 \mathrm{D}$ and Table 2 ). The MES solution $\left(\chi^{2}=4.5\right)$ for the LigIII ${ }_{755^{-}}$ DNA complex is a mixture of open and closed forms of the $\Delta \mathrm{ZnF}_{755}$-DNA complex with the $\mathrm{ZnF}$ domain highly extended in all selected conformers (Figure $4 \mathrm{~F}$ ). This ensemble accounts for the elongated tail of the experimental $\mathrm{P}(\mathrm{r})$ curve at large distances. Thus the $\mathrm{ZnF}$ domain exists in a flexible, elongated conformation that significantly extends the molecular envelope of the LigIII protein both in the presence and absence of DNA. The $\mathrm{ZnF}$ does not stably bind to DNA when the DBD, OBD and NTase encircle nicked DNA.

\section{Discussion}

Mammalian DNA ligases I and III have non-redundant functions in DNA replication and repair, yet these enzymes exhibit remarkably similar structures. There is extensive evidence that protein-protein interactions involving the regions that flank the conserved catalytic region target the three mammalian DNA ligases to different DNA transactions (38). In contrast, much less is known about how differences in the catalytic properties of the DNA ligases contribute to their cellular functions. LigI and LigIII have different substrate 
specificities and DNA binding properties that can be traced to individual domains that constitute these structurally related enzymes. We propose these functional adaptations of LigIII reflect the presence of an $\mathrm{N}$-terminal $\mathrm{ZnF}$ that is critical for the participation of ligase III in the repair of single- and double-strand breaks.

The crystal structure of the LigIII-DNA complex supports and extends knowledge about the core NTase and OBD domains of mammalian ligases that harbor active site residues found in all members of the superfamily of nucleotidyl transferases (12). We show that the DBD has a conserved protein fold and mode of interaction with a nicked DNA (Figure 1,2), despite the low amino acid sequence homology in this region (13). The DBD is the common element of two different modes of DNA binding--nick sensing by the ZnF-DBD and catalysis of DNA end joining by the DBD-NTase-OBD domains (15). The switch between these binding modes is likely assisted by the flexible structure of DNA ligase III, which was revealed by small angle x-ray scattering experiments. The complex of LigIII with DNA in solution shows evidence of multiple conformers (Figure 4), including the closed conformation seen in the crystal structure and partially open conformations that are suggestive of dynamic interactions with the nicked DNA. The DBD may provide an anchoring interaction with DNA that enables flanking domains to exchange on and off the nicked DNA strand without complete dissociation of LigIII from the DNA.

Our biophysical studies show the ZnF does not stably bind to DNA or pack against LigIII when the catalytic domains are clamped around the DNA nick. The ZnF and DBD together constitute an independent DNA end-binding module with supra-additive affinity in comparison to the individual $\mathrm{ZnF}$ and DBD domains (15). A computational model of the ZnF-DBD interaction with DNA (Figure 5) makes the strong prediction that this DNA interaction precludes the nick binding mode revealed by the crystal structure of the catalytic core of LigIII (Figure 1). This model supports the proposed conformational switching between nick-sensing and nick sealing modes of DNA engagement that is illustrated by the jackknife model (Figure 5). The $\mathrm{ZnF}$ is predicted to bind DNA through a positively charged, concave surface that is made up of a $\beta$-sheet, helix 1 and the apical loop connecting $\beta 2$ to $\beta 3$ (17). We positioned the $\mathrm{ZnF}$ so that its positive face contacts the DNA and the apical loop inserts into the minor groove of DNA opposite the nick, in a manner analogous to the OBD domain of the $\triangle \mathrm{ZnF}$-LigIII crystal structure (Figure $\mathrm{S} 2$ ). In this orientation, the $\mathrm{ZnF}$ and DBD form a continuous, $\mathrm{C}$-shaped surface that is positively charged and complementary to the underwound DNA from the crystal structure. This docking model places residues in contact with the DNA whose NMR resonances were strongly perturbed by the presence of a nicked DNA (17). The apical loop of the $\mathrm{ZnF}$ is too wide $(8 \AA)$ to fit into the minor groove of B-form DNA ( $4 \AA$ ), but it is accommodated by the widened minor groove at the site where the OBD binds. The apical loop of the $\mathrm{ZnF}$ may therefore serve as a probe for flexible DNA structures that can accommodate a widening of the minor groove. Consistent with this idea, the $\mathrm{ZnF}$ of DNA ligase III and similar PARP-family zinc fingers bind to irregular structures in DNA, including nicks, single-stranded gaps, and DNA hairpins $(18,39,40)$. The docking model places the C-terminus of the $\mathrm{ZnF}$ within $50 \AA$ of the N-terminus of the DBD, a distance readily spanned by the 73-residue linker missing from structures of the $\mathrm{ZnF}$ domain and $\Delta \mathrm{ZnF}$-LigIII protein (Figure $5 \mathrm{~A}$ ). In this position, the $\mathrm{ZnF}$ sterically excludes the NTase domain and OBD from binding to DNA. Our studies have identified a unique positively charged groove in the DBD of LigIII, which functionally interacts with the $\mathrm{ZnF}$ to promote the ligation of a blunt ended DNA (Figure 3). We suggest that this groove may provide a docking site that transiently positions the $\mathrm{ZnF}$ on DNA during nick-sensing (Figure 5B) or during capture of two DNA molecules for intermolecular ligation (Figure $5 \mathrm{C})$. 
Although the addition of the purified ZnF in trans inhibits DNA joining by $\Delta \mathrm{ZnF}-\mathrm{LigIII} \beta$, the $\mathrm{ZnF}$ domain of LigIII $\beta$ enhances nick-joining activity, in particular at higher salt concentrations (15). To explain this apparent paradox, we proposed a sequential handoff of the DNA from the initial nick sensing by the ZnF-DBD to the engagement of the DNA nick by the catalytic core (15). In this model, the flat DNA-binding surface of the DBD acts as a platform that presents the DNA to different domains of ligase III during each step of DNA end joining. This proposed mechanism of ZnF-dependent loading of ligase III onto DNA is named the "jackknife model," which likens LigIII to a pocketknife with multiple domains that have specialized functions during the ligation reaction. The crystal structure and SAXS data clearly demonstrate that the closed conformation of LigIII, with the conserved domains (DBD-NTase-OBD) encircling the nicked DNA, precludes binding by the $\mathrm{ZnF}$. The jackknife model attempts to reconcile the functional importance of the $\mathrm{ZnF}$ for substrate discrimination and catalytic efficiency of LigIII with the apparent transient nature of interactions between the $\mathrm{ZnF}$ and the DNA substrate. We suggest that the conformational flexibility of LigIII revealed by SAXS experiments (Figure 4) enables LigIII to efficiently undergo the large scale, dynamic changes necessary to transition between these two structurally distinct DNA binding modes, nick-sensing and nick ligation. This two-step break recognition mechanism is important primarily for DNA breaks that require further processing prior to ligation. Our docking model of the ZnF-DBD bound to DNA suggests that the ZnF might sense DNA flexibility by inserting into the minor groove, enabling selective binding to gaps, flaps, bulges, or double strand breaks (Figure 5).

Though the requirement for the $\mathrm{ZnF}$ in ligation of nicks remains unclear, the $\mathrm{ZnF}$ is absolutely required for the intermolecular joining of blunt ended DNA molecules (15). Here we envision that the two DNA binding modules of ligase III, spanning the ZnF-DBD and the NTase-OBD regions (15), could bridge between two DNA molecules and align them for ligation by the DBD-NTase-OBD domains, in a manner analogous to the nick joining reaction depicted by the crystal structure (Figure 5B). This intermolecular joining activity of LigIII is compatible with its involvement in an alternative non-homologous end joining pathway that repairs DNA double strand breaks (2). Interestingly, this alternative to the dominant, $\mathrm{Ku}$-dependent pathway generates large deletions and chromosomal translocations, genomic rearrangements that are frequently detected in a cancer cells (41). In addition, cancer cells appear to be more dependent upon this pathway for the repair of DNA double strand breaks than normal cells (3), suggesting that cancer cells will be hypersensitive to inhibitors of backup NHEJ. Our biochemical and biophysical studies delineating the roles of the $\mathrm{ZnF}$ and DBD in intermolecular ligation by LigIII provide a rationale for the identification of small molecules that target the $\mathrm{ZnF}$ and/or the positively-charged groove in the DBD as selective inhibitors of alternative non-homologous end-joining.

Although the core structure of DNA ligase III is based on the same framework as other mammalian ligases, this enzyme has unique adaptations that contribute to the catalytic properties of LigIII, improving the catalytic efficiency of DNA single strand break repair and enabling efficient ligation of two blunt-ended DNAs (15). These distinctive DNA binding and enzymatic properties of ligase III contribute to its biological specialization, in addition to protein-protein interactions that target the enzyme to sites of DNA damage. Alternative modes of DNA interaction may also contribute to the fidelity of DNA end joining and provide opportunities for regulating ligation activity to prevent the formation of dead end intermediates that inhibit repair of the break (42). The flexible structure of ligase III may facilitate recruitment to single-strand breaks while leaving the DNA accessible to other modifying enzymes for a sequential hand-off of repair intermediates that promotes efficient repair of DNA damage while avoiding toxic or mutagenic outcomes.

Understanding these biologically important handoffs, which may also be critical for base excision repair $(43,44)$, will require the integration of structural models of conformational 
change with the rates and mechanisms of enzymatic functions, as developed here for DNA ligase III using crystallography, SAXS, and mutational analyses.

\section{Supplementary Material}

Refer to Web version on PubMed Central for supplementary material.

\section{Acknowledgments}

John Pascal kindly provided us with RNA substrates.

\section{Abbreviations}

$\begin{array}{ll}\text { LigIII } & \text { DNA ligase III } \\ \text { NTase } & \text { nucleotidyl transferase domain } \\ \text { OBD } & \text { oligonucleotide binding domain } \\ \text { DBD } & \text { DNA binding domain } \\ \text { ZnF } & \text { zinc finger domain } \\ \text { NHEJ } & \text { nonhomologous end joining } \\ \text { BRCT } & \text { BRCA1-related C-terminal domain } \\ \text { LigI } & \text { DNA ligase I } \\ \text { LigIV } & \text { DNA ligase IV } \\ \text { SAXS } & \text { small angle x-ray scattering } \\ \text { PARP1 } & \text { poly (ADP-ribose) polymerase I }\end{array}$

\section{References}

1. Tomkinson AE, Vijayakumar S, Pascal JM, Ellenberger T. DNA ligases: structure, reaction mechanism, and function. Chemical Reviews. 2006; 106:687-699. [PubMed: 16464020]

2. Wang H, Rosidi B, Perrault R, Wang M, Zhang L, Windhofer F, Iliakis G. DNA ligase III as a candidate component of backup pathways of nonhomologous end joining. Cancer Research. 2005; 65:4020-4030. [PubMed: 15899791]

3. Sallmyr A, Tomkinson AE, Rassool FV. Up-regulation of WRN and DNA ligase IIIalpha in chronic myeloid leukemia: consequences for the repair of DNA double-strand breaks. Blood. 2008; 112:1413-1423. [PubMed: 18524993]

4. Puebla-Osorio N, Lacey DB, Alt FW, Zhu C. Early embryonic lethality due to targeted inactivation of DNA ligase III. Molecular and Cellular Biology. 2006; 26:3935-3941. [PubMed: 16648486]

5. Dulic A, Bates PA, Zhang X, Martin SR, Freemont PS, Lindahl T, Barnes DE. BRCT domain interactions in the heterodimeric DNA repair protein XRCC1-DNA ligase III. Biochemistry. 2001; 40:5906-5913. [PubMed: 11352725]

6. Nash RA, Caldecott KW, Barnes DE, Lindahl T. XRCC1 protein interacts with one of two distinct forms of DNA ligase III. Biochemistry. 1997; 36:5207-5211. [PubMed: 9136882]

7. Mackey ZB, Ramos W, Levin DS, Walter CA, McCarrey JR, Tomkinson AE. An alternative splicing event which occurs in mouse pachytene spermatocytes generates a form of DNA ligase III with distinct biochemical properties that may function in meiotic recombination. Molecular and Cellular Biology. 1997; 17:989-998. [PubMed: 9001252]

8. Husain I, Tomkinson AE, Burkhart WA, Moyer MB, Ramos W, Mackey ZB, Besterman JM, Chen J. Purification and characterization of DNA ligase III from bovine testes. Homology with DNA 
ligase II and vaccinia DNA ligase. The Journal of Biological Chemistry. 1995; 270:9683-9690. [PubMed: 7721901]

9. Lakshmipathy U, Campbell C. Mitochondrial DNA ligase III function is independent of Xrcc1. Nucleic Acids Research. 2000; 28:3880-3886. [PubMed: 11024166]

10. Lakshmipathy U, Campbell C. The human DNA ligase III gene encodes nuclear and mitochondrial proteins. Molecular and Cellular Biology. 1999; 19:3869-3876. [PubMed: 10207110]

11. McKinnon PJ, Caldecott KW. DNA strand break repair and human genetic disease. Annu Rev Genomics Hum Genet. 2007; 8:37-55. [PubMed: 17887919]

12. Shuman S, Schwer B. RNA capping enzyme and DNA ligase: a superfamily of covalent nucleotidyl transferases. Molecular Microbiology. 1995; 17:405-410. [PubMed: 8559059]

13. Martin IV, MacNeill SA. ATP-dependent DNA ligases. Genome Biology. 2002; 3:REVIEWS3005. [PubMed: 11983065]

14. Pascal JM, O'Brien PJ, Tomkinson AE, Ellenberger T. Human DNA ligase I completely encircles and partially unwinds nicked DNA. Nature. 2004; 432:473-478. [PubMed: 15565146]

15. Cotner-Gohara E, Kim IK, Tomkinson AE, Ellenberger T. Two DNA-binding and nick recognition modules in human DNA ligase III. The Journal of Biological Chemistry. 2008; 283:10764-10772. [PubMed: 18238776]

16. Mackey ZB, Niedergang C, Murcia JM, Leppard J, Au K, Chen J, de Murcia G, Tomkinson AE. DNA ligase III is recruited to DNA strand breaks by a zinc finger motif homologous to that of poly(ADP-ribose) polymerase. Identification of two functionally distinct DNA binding regions within DNA ligase III. The Journal of Biological Chemistry. 1999; 274:21679-21687. [PubMed: 10419478]

17. Kulczyk AW, Yang JC, Neuhaus D. Solution structure and DNA binding of the zinc-finger domain from DNA ligase IIIalpha. Journal of Molecular Biology. 2004; 341:723-738. [PubMed: 15288782]

18. Taylor RM, Whitehouse CJ, Caldecott KW. The DNA ligase III zinc finger stimulates binding to DNA secondary structure and promotes end joining. Nucleic Acids Research. 2000; 28:35583563. [PubMed: 10982876]

19. Van Duyne GD, Standaert RF, Karplus PA, Schreiber SL, Clardy J. Atomic structures of the human immunophilin FKBP-12 complexes with FK506 and rapamycin. Journal of Molecular Biology. 1993; 229:105-124. [PubMed: 7678431]

20. Otwinowski Z, Minor W. Processing of X-ray Diffraction Data Collected in Oscillation Mode. Methods in Enzymology. 1997; 276:307-326.

21. Pflugrath JW. The finer things in X-ray diffraction data collection. Acta Crystallographica. 1999; 55:1718-1725.

22. Terwilliger TC, Berendzen J. Automated MAD and MIR structure solution. Acta Crystallographica. 1999; 55:849-861.

23. de La Fortelle, E.; Bricogne, G.; Carter, Charles W, Jr. Methods in Enzymology. Academic Press; 1997. [27] Maximum-likelihood heavy-atom parameter refinement for multiple isomorphous replacement and multiwavelength anomalous diffraction methods; p. 472-494.

24. Emsley P, Cowtan K. Coot: model-building tools for molecular graphics. Acta Crystallographica. 2004; 60:2126-2132.

25. Murshudov GN, Vagin AA, Dodson EJ. Refinement of macromolecular structures by the maximum-likelihood method. Acta Crystallographica. 1997; 53:240-255.

26. Baker NA, Sept D, Joseph S, Holst MJ, McCammon JA. Electrostatics of nanosystems: application to microtubules and the ribosome. Proceedings of the National Academy of Sciences of the United States of America. 2001; 98:10037-10041. [PubMed: 11517324]

27. Hura GL, Menon AL, Hammel M, Rambo RP, Poole FL 2nd, Tsutakawa SE, Jenney FE Jr, Classen S, Frankel KA, Hopkins RC, Yang SJ, Scott JW, Dillard BD, Adams MW, Tainer JA. Robust, high-throughput solution structural analyses by small angle X-ray scattering (SAXS). Nature Methods. 2009; 6:606-612. [PubMed: 19620974]

28. Guinier, A.; Fournet, F. Small Angle Scattering of X-rays. Wiley Interscience; New York: 1955.

29. Svergun D. Determination of the regularization Parameter in Indirect-Transform Methods using perceptual criteria. J Appl Cryst. 1992; 25:495-503. 
30. Pelikan M, Hura GL, Hammel M. Structure and Flexibility within proteins as identified through small angle X-ray scattering. General Physiology and Biophysics. 2009; 28:174-189. [PubMed: 19592714]

31. Nandakumar J, Nair PA, Shuman S. Last stop on the road to repair: structure of E. coli DNA ligase bound to nicked DNA-adenylate. Molecular Cell. 2007; 26:257-271. [PubMed: 17466627]

32. Nair PA, Nandakumar J, Smith P, Odell M, Lima CD, Shuman S. Structural basis for nick recognition by a minimal pluripotent DNA ligase. Nature Structural \& Molecular Biology. 2007

33. Tomkinson AE, Roberts E, Daly G, Totty NF, Lindahl T. Three distinct DNA ligases in mammalian cells. The Journal of Biological Chemistry. 1991; 266:21728-21735. [PubMed: 1939197]

34. Bhagwat AS, Sanderson RJ, Lindahl T. Delayed DNA joining at 3' mismatches by human DNA ligases. Nucleic Acids Research. 1999; 27:4028-4033. [PubMed: 10497267]

35. Koch MH, Vachette P, Svergun DI. Small-angle scattering: a view on the properties, structures and structural changes of biological macromolecules in solution. Q Rev Biophys. 2003; 36:147-227. [PubMed: 14686102]

36. Putnam CD, Hammel M, Hura GL, Tainer JA. X-ray solution scattering (SAXS) combined with crystallography and computation: defining accurate macromolecular structures, conformations and assemblies in solution. Quarterly Reviews of Biophysics. 2007; 40:191-285. [PubMed: 18078545]

37. Pelikan M, Hura GL, Hammel M. Structure and flexibility within proteins as identified through small angle X-ray scattering. Gen Physiol Biophys. 2009; 28:174-189. [PubMed: 19592714]

38. Ellenberger T, Tomkinson AE. Eukaryotic DNA ligases: structural and functional insights. Annual Review of Biochemistry. 2008; 77:313-338.

39. Petrucco S. Sensing DNA damage by PARP-like fingers. Nucleic Acids Research. 2003; 31:66896699. [PubMed: 14627802]

40. Petrucco S, Volpi G, Bolchi A, Rivetti C, Ottonello S. A nick-sensing DNA 3'-repair enzyme from Arabidopsis. The Journal of Biological Chemistry. 2002; 277:23675-23683. [PubMed: 11948185]

41. Wang H, Perrault AR, Takeda Y, Qin W, Wang H, Iliakis G. Biochemical evidence for Kuindependent backup pathways of NHEJ. Nucleic Acids Research. 2003; 31:5377-5388. [PubMed: 12954774]

42. Ahel I, Rass U, El-Khamisy SF, Katyal S, Clements PM, McKinnon PJ, Caldecott KW, West SC. The neurodegenerative disease protein aprataxin resolves abortive DNA ligation intermediates. Nature. 2006; 443:713-716. [PubMed: 16964241]

43. Garcin ED, Hosfield DJ, Desai SA, Haas BJ, Bjoras M, Cunningham RP, Tainer JA. DNA apurinic-apyrimidinic site binding and excision by endonuclease IV. Nature Structural \& Molecular Biology. 2008; 15:515-522.

44. Parikh SS, Putnam CD, Tainer JA. Lessons learned from structural results on uracil-DNA glycosylase. Mutation Research. 2000; 460:183-199. [PubMed: 10946228]

45. Ciarrocchi G, Lestingi M, Wright G, Montecucco A. Bacteriophage T4 and human type I DNA ligases relax DNA under joining conditions. Nucleic Acids Research. 1993; 21:5934-5939. [PubMed: 8290355] 

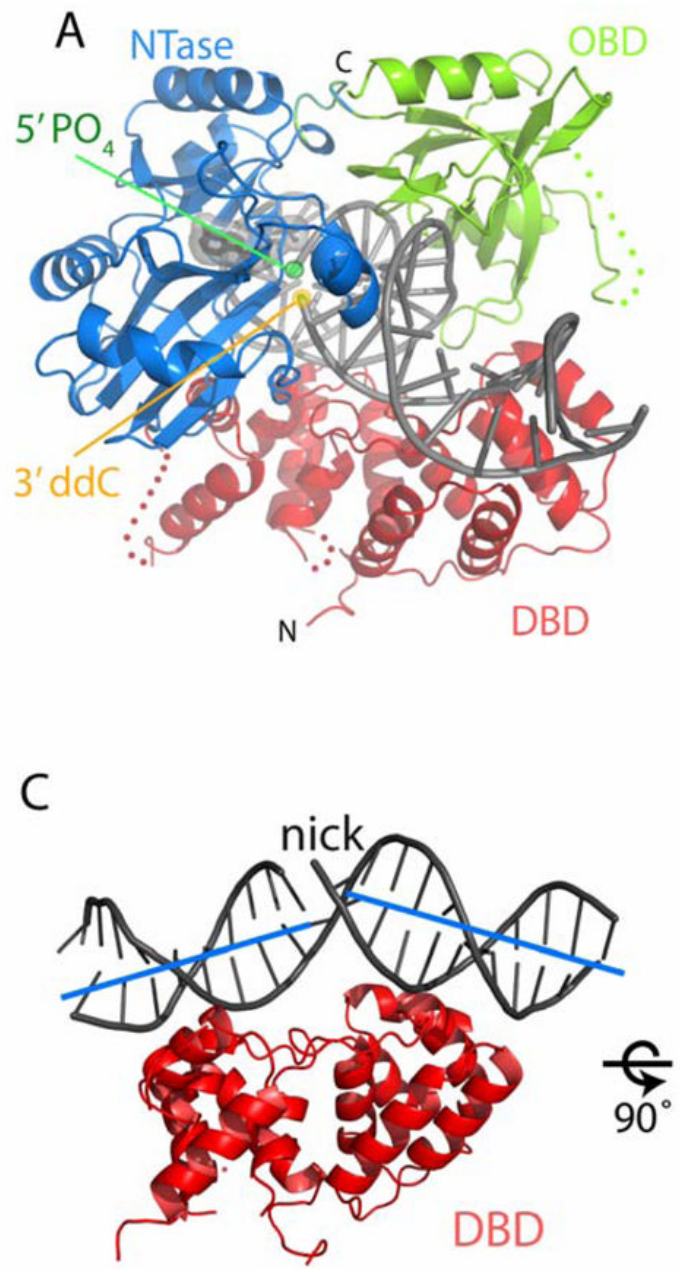

B
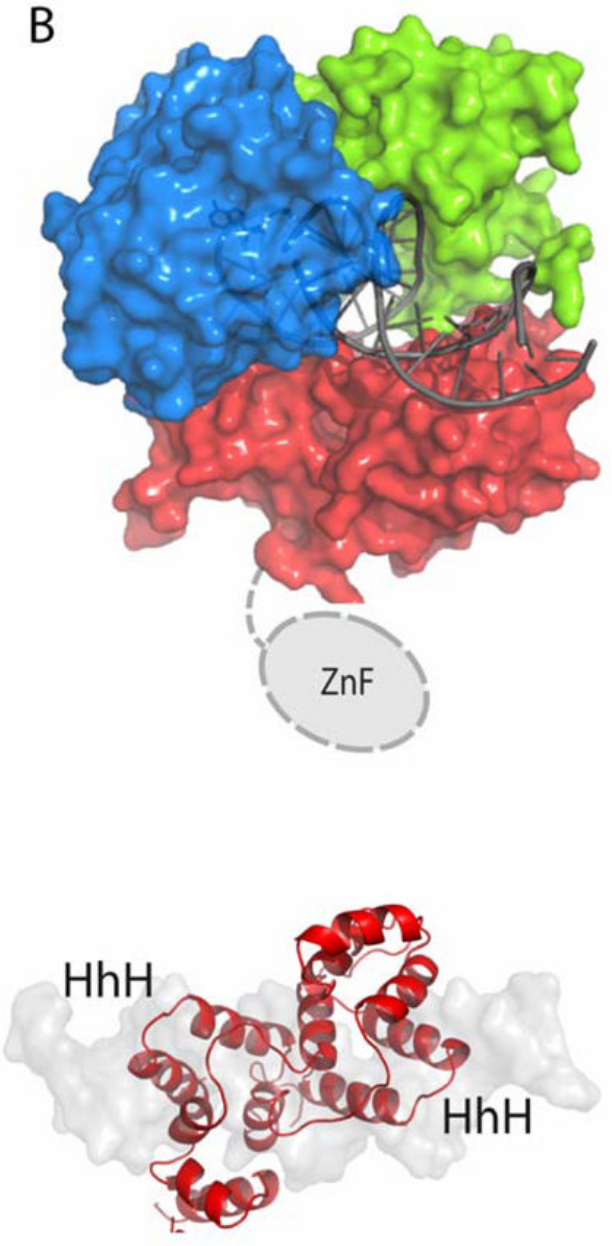

Figure 1. The structure of $\triangle \mathrm{ZnF}$-LigIII $\beta$ bound to DNA

(A) Ligase III bound to a nicked DNA substrate. The adenylated $\triangle \mathrm{ZnF-Ligase} \mathrm{III} \beta$ protein was captured in a pre-Step 2 complex with DNA prior to transfer of AMP to the DNA. The 5' PO4 and 3' ddC termini of the nicked DNA strand are highlighted in green and yellow, respectively. The crystallographic model contains 537 residues of the 697-residue protein fragment that was crystallized and 43 of the 44 nucleotides. The C-terminal 100 amino acids (residues 747-862) are disordered, indicating that this region is flexible. However, comparison to ligase homologues indicates that the entire OBD domain is observed. In addition, there are three disordered loops in the protein: two in the DNA-binding domain (DBD; residues 207-213 and 376-383) and one in the OB-fold domain (OBD; residues 666-691). All three of these loops are located on the exterior of the protein, away from the DNA and domain interfaces. (B) The surface view of $\triangle \mathrm{ZnF}$-Ligase III $\beta$ bound to DNA shows that Ligase III forms a continuous ring about the DNA during Step 2 with the nicked DNA strand sequestered in the active site pocket of the NTase domain. (C) The DBD of Ligase III forms a platform for the highly distorted DNA, which is partially unwound and has an offset in the helical axis about the nick (left). The DBD interacts with the DNA through two helix-hairpin-helix motifs that insert into the minor groove on either side of the nick (45). 


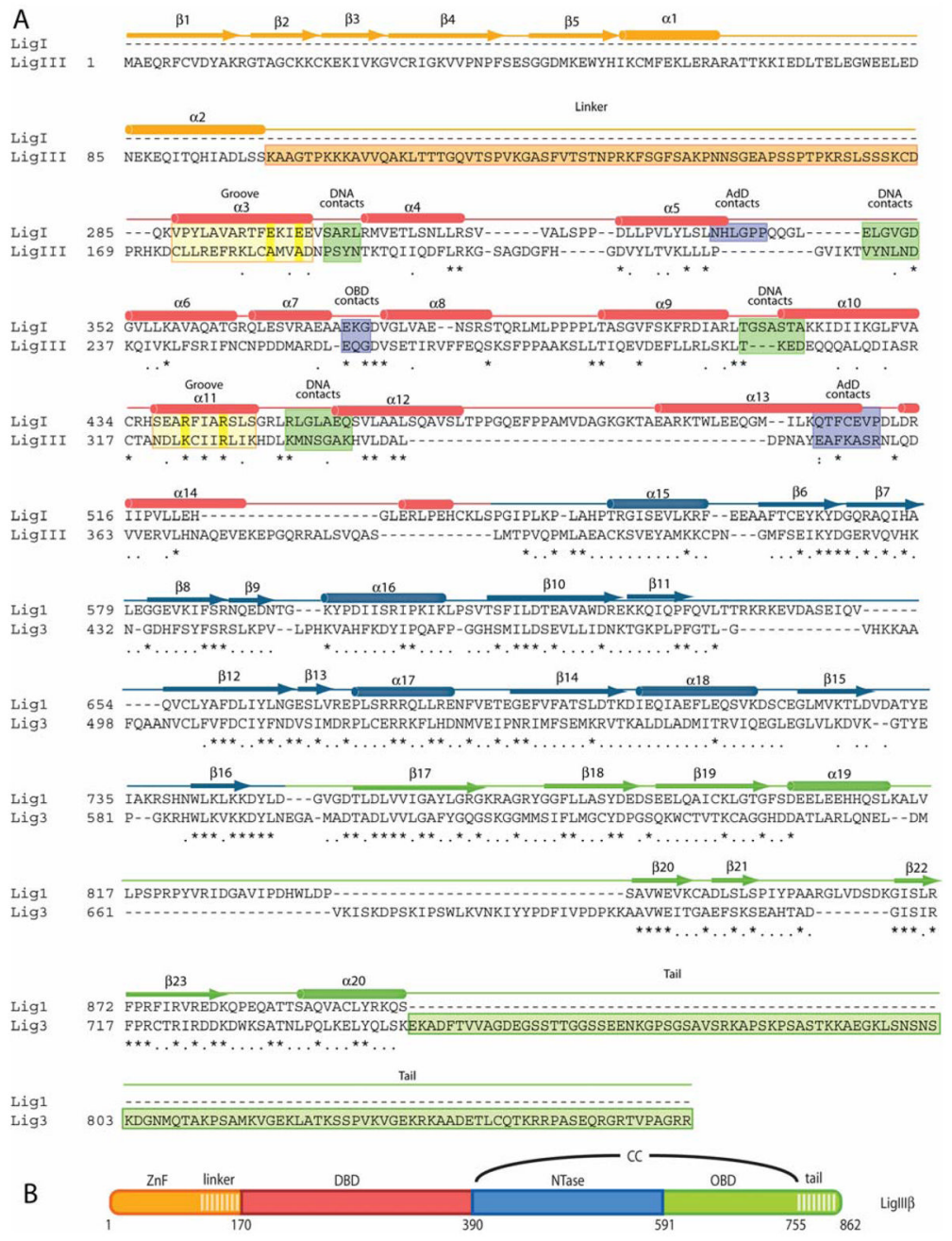

Figure 2. Human LigIII structural alignment to human LigI

(A) Structural alignment of LigI and LigIII shows the contrast between the high sequence conservation of the NTase and OBD domains and the low sequence conservation of the DBD domain. The secondary structure of LigIII, colored-coded by domain, is indicated above the amino acid sequence. Residues contacting DNA (green) or other domains (purple) are highlighted. The two helices that form a positively charged groove in unique to ligase III are highlighted in yellow, with key residues highlighted in bright yellow. (B) The domain structure of ligase III. 
A

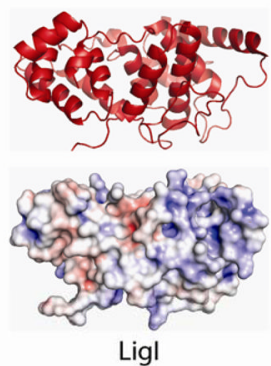

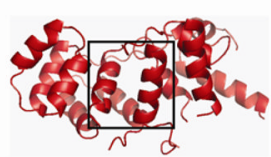

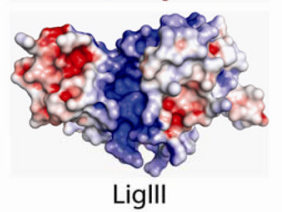

B
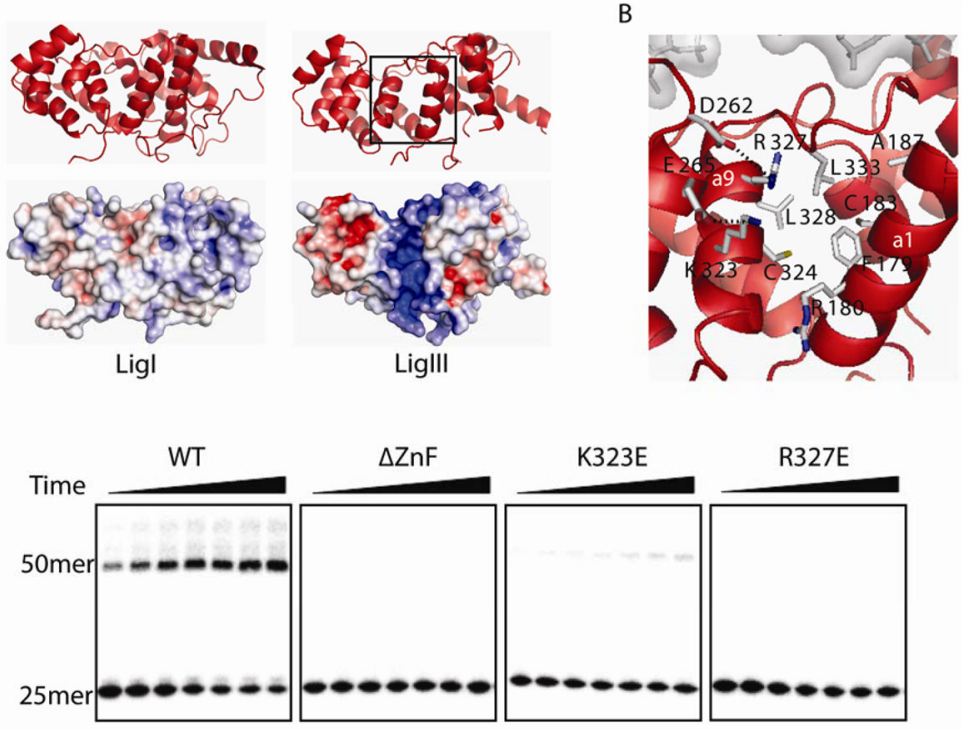

D

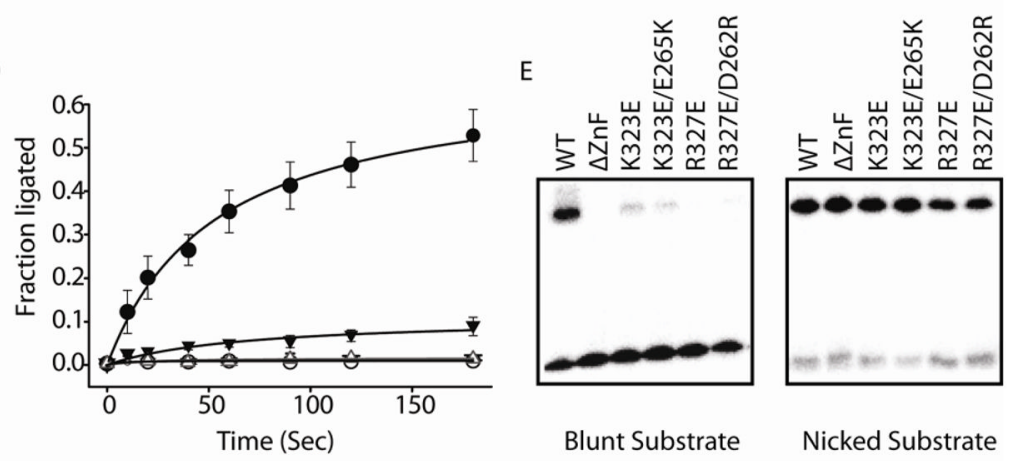

Figure 3. A unique positively charged groove in the DBD is important for intermolecular DNA ligation

(A) Structural comparison of DBDs between ligase I (left) and ligase III reveals a unique positively charged groove of ligase III. (B) Close view of the positively charged groove, which is boxed in (A). (C) LigIII $\beta, \Delta \mathrm{ZnF}$, and two mutants of LigIII $\beta$ (K323E and R327E) with residue substitutions in the positively charged groove were assayed for blunt-end joining activity in a single turnover assay. $100 \mathrm{nM}$ of proteins were reacted with $4 \mathrm{nM}$ DNA substrates at $22{ }^{\circ} \mathrm{C}$ with different time points $(10 \mathrm{sec}, 20 \mathrm{sec}, 40 \mathrm{sec}, 1 \mathrm{~min}, 1.5 \mathrm{~min}, 2 \mathrm{~min}$ and $3 \mathrm{~min}$ ). (D) The ligated fraction for each protein each protein in (C) [WT (•), $\Delta \mathrm{ZnF}(\mathrm{\circ})$, $\mathrm{K} 323 \mathrm{E}(\boldsymbol{\nabla})$ and R327E $(\Delta)$ ] is plotted. Error bars are standard deviations from three separate experiments. (E) The reciprocal charge-reversal mutants (K323E/E265K and R327E/D262R) and their parental single mutants were assayed for blunt-end and nick joining activity. $100 \mathrm{nM}$ protein were reacted with DNA substrates at $22{ }^{\circ} \mathrm{C}$ for $1.5 \mathrm{~min}$. 
A
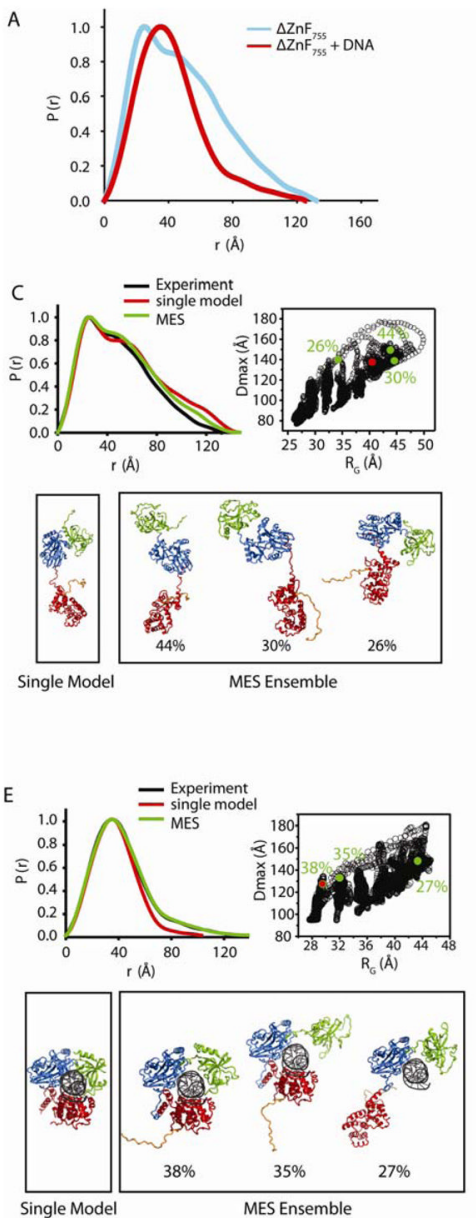

B
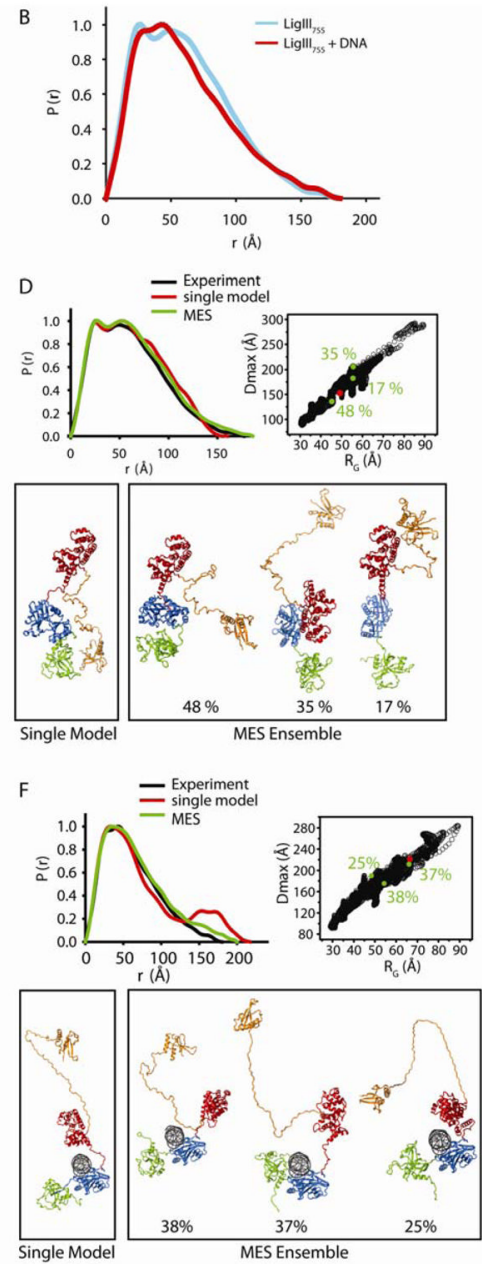

Figure 4. Small angle $X$-ray scattering of LigIII domains and DNA substrate complexes (A) Normalized pair distribution $(\mathrm{P}(\mathrm{r}))$ functions for the $\Delta \mathrm{ZnF}_{755}$ protein in the presence and absence of DNA reveal a large conformational transition of the three conserved domains of LigIII (DBD-NTase-OBD) from an extended to a compact structure. (B) Comparisons of $\mathrm{P}(\mathrm{r})$ functions for $\mathrm{LigIII}_{755}$ in the presence and absence of DNA show that ZnF-containing LigIII proteins are elongated even when bound to DNA, suggesting that the $\mathrm{ZnF}$ adopts flexible conformations during end joining. (C-F) Rigid body modeling of $\Delta \mathrm{ZnF}_{755}$ (C), $\mathrm{LigIII}_{755}$ (D), $\Delta \mathrm{ZnF}_{755}$-DNA complex (E), and LigIII 755 -DNA complex (F) by MD simulation and MES. For each protein complex, the top left panel shows a comparison of the experimental $\mathrm{P}(\mathrm{r})$ curve with those calculated from single best fit model (red) or the MES ensemble (green). In the $\Delta \mathrm{ZnF}_{755}$-DNA complex (E), the crystal structure of LigIII $\beta \Delta \mathrm{ZnF}$ DNA complex is used as the single model. In the top right panel, a comparison of $\mathrm{D}_{\max }$ values for 10,000 models with their $\mathrm{R}_{\mathrm{g}}$ values is shown. The best single model and the best fit group of MES conformers are indicated by red and green circles, respectively, with their relative volume fractions. The bottom panels show the single best fit model and three MES conformers with their relative volume fractions. The LigIII domains are colored as in Figure 2 . 


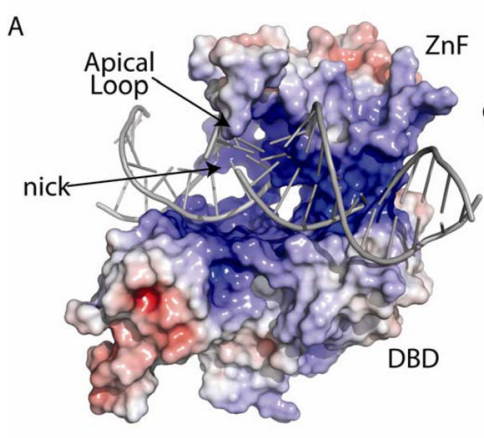

A

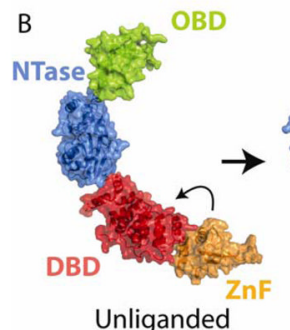

Unliganded

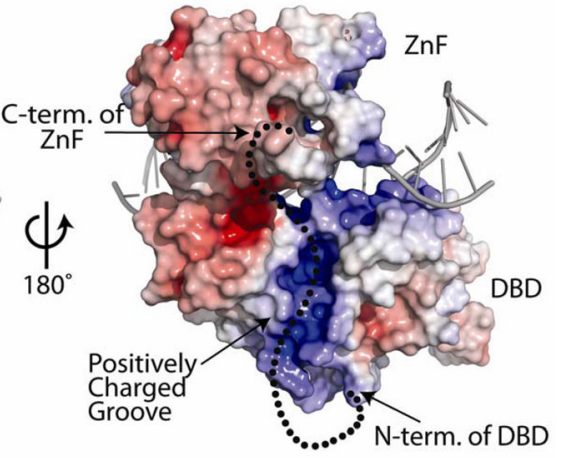

C

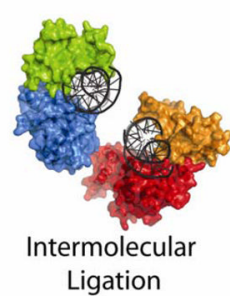

Figure 5. Jackknife Mechanism of DNA Substrate Recognition

(A) Model of nick sensing by LigIII. The ZnF solution structure (PDB ID: 1uw0) was docked onto the DBD and DNA from the $\triangle \mathrm{ZnF}$ crystal structure to demonstrate how the ZnF-DBD module could bind to DNA in a nick-sensing mode. 73 residues of ligase III are missing from the two structures used to construct the model. This missing linker between the $\mathrm{ZnF}$ and NTase domains may interact with the positively charged groove in the DBD, as indicated by the black dots. (B) Unliganded ligase III adopts an extended conformation, as demonstrated by SAXS experiments. In the substrate recognition step, the $\mathrm{ZnF}$ is proposed to insert into the minor groove at the nick, recognizing flexibility in the DNA substrate. In the catalytic step, we hypothesize that the $\mathrm{ZnF}$ disengages to allow the DBD, NTase and OBD to fully encircle the nick, resembling in the $\triangle \mathrm{ZnF}$ crystal structure. (C) The two DNA binding regions of ligase III (the ZnF-DBD and NTase-OBD) could allow simultaneous binding of two DNAs to stimulate intermolecular ligations. 


\begin{tabular}{|c|c|c|c|c|c|c|c|c|c|c|c|c|c|c|c|}
\hline \multirow{3}{*}{ 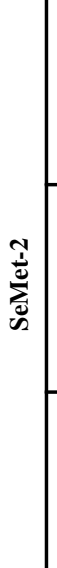 } & $\begin{array}{l}\Sigma \\
\Sigma \\
\Sigma\end{array}$ & 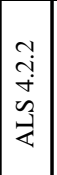 & 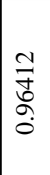 & $\begin{array}{l}\widehat{\tilde{n}} \\
\tilde{1} \\
\tilde{m} \\
\tilde{n} \\
\tilde{n} \\
\tilde{n}\end{array}$ & 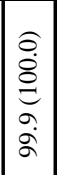 & 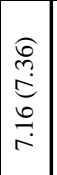 & $\stackrel{\overbrace =}{\sim}$ & 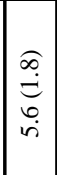 & $\stackrel{\overbrace{}}{\sim}$ & 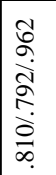 & 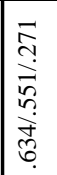 & & & & \\
\hline & $\frac{\text { ș }}{\stackrel{s}{\Sigma}}$ & 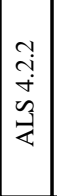 & $\begin{array}{l}n \\
\tilde{\hat{\alpha}} \\
\hat{\sigma} \\
\delta\end{array}$ & 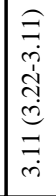 & 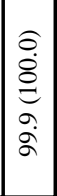 & 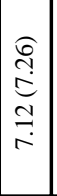 & 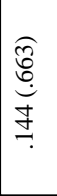 & $\mid \begin{array}{l}\hat{\sigma} \\
\dot{d} \\
\hat{d} \\
\dot{b}\end{array}$ & $\underset{\sim}{\vec{\rho}}$ & 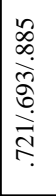 & 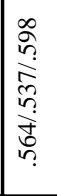 & & & & \\
\hline & $\frac{\bar{z}}{\bar{z}}$ & 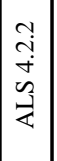 & $\begin{array}{l}\bar{\sigma} \\
\bar{\Omega} \\
\hat{\sigma} \\
0\end{array}$ & 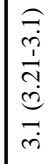 & 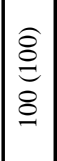 & 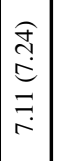 & 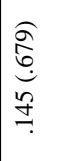 & 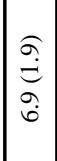 & $\frac{\rho}{m}$ & 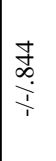 & $\underset{i}{\stackrel{8}{O}}$ & & & & \\
\hline 永 & & 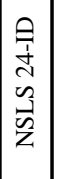 & $\begin{array}{l}\overline{\hat{\alpha}} \\
\hat{\sigma}\end{array}$ & 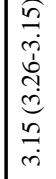 & $\left|\begin{array}{|l}\hat{y} \\
\hat{\delta} \\
\hat{\delta} \\
\delta\end{array}\right|$ & $\begin{array}{l}\stackrel{f}{d} \\
\stackrel{d}{m} \\
\stackrel{n}{n}\end{array}$ & 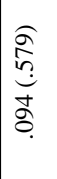 & $\begin{array}{l}\stackrel{\sigma}{\mathcal{C}} \\
\stackrel{\sim}{=} \\
=\end{array}$ & $\frac{n}{n}$ & & & & & & \\
\hline 至 & & $\begin{array}{l}a \\
a \\
\sim \\
c \\
u \\
\tilde{n} \\
z\end{array}$ & $\begin{array}{l}\overline{\hat{\alpha}} \\
\hat{\alpha} \\
0\end{array}$ & 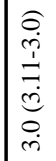 & $\mid \begin{array}{l}n \\
n \\
\tilde{n} \\
n \\
n \\
\alpha \\
\end{array}$ & 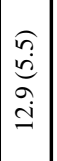 & 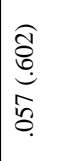 & 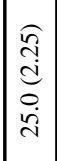 & $\underset{\sim}{\stackrel{\infty}{~}}$ & $\begin{array}{l}\text { के } \\
\infty \\
\infty \\
\grave{d} \\
\infty \\
\infty\end{array}$ & 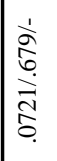 & \begin{tabular}{|l|}
8 \\
$\dot{m}$
\end{tabular} & 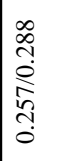 & $\mid \begin{array}{l}\tilde{o} \\
\dot{o} \\
\dot{0}\end{array}$ & $\mid \begin{array}{l}0 \\
\stackrel{\infty}{0} \\
0 \\
0\end{array}$ \\
\hline
\end{tabular}
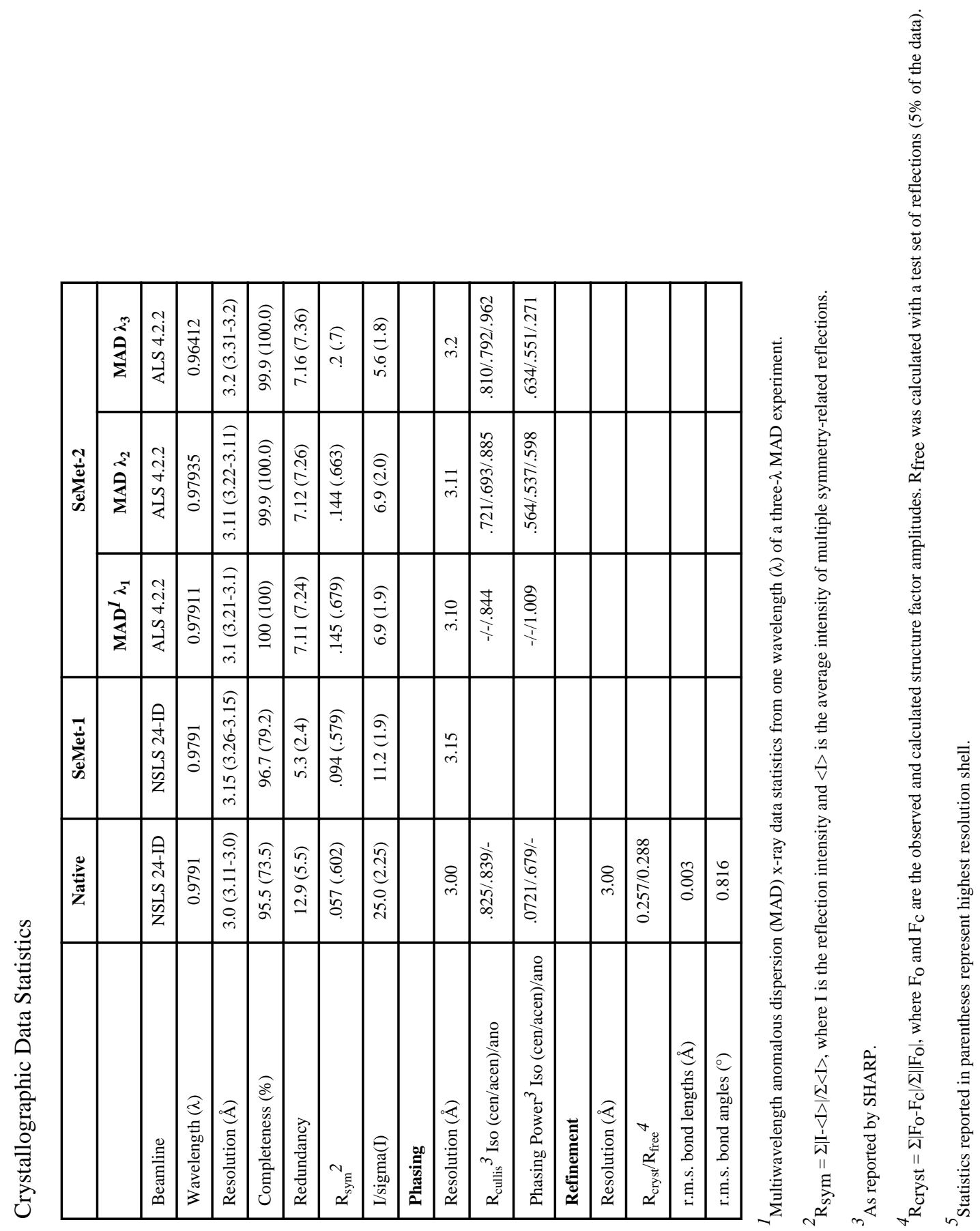

Biochemistry. Author manuscript; available in PMC 2011 July 27. 
Table 2

Structural parameters from SAXS data

\begin{tabular}{|c|c|c|c|}
\hline \multirow[b]{2}{*}{ SAXS sample } & \multicolumn{2}{|c|}{ Experimental parameters } & \multirow{2}{*}{$\begin{array}{c}\text { Rigid body modeling } \\
\chi^{2} \text { single model/MES }\end{array}$} \\
\hline & $\mathbf{D}_{\max }(\AA)$ & $\mathbf{R}_{\mathrm{g}}(\AA)$ & \\
\hline LigIII $\beta$ & $\sim 194$ & $48.5 \pm 0.2$ & \\
\hline $\operatorname{LigIII} \beta+\mathrm{DNA}$ & $\sim 195$ & $48.4 \pm 0.2$ & \\
\hline $\operatorname{LigIII}_{755}$ & $\sim 177$ & $45.5 \pm 0.2$ & $6.1 / 3.9$ \\
\hline $\operatorname{LigIII}_{755}+\mathrm{DNA}$ & $\sim 180$ & $45.9 \pm 0.2$ & $6.3 / 4.5$ \\
\hline$\Delta \mathrm{ZnF}$ & $\sim 167$ & $42.9 \pm 0.3$ & \\
\hline$\Delta \mathrm{ZnF}+\mathrm{DNA}$ & $\sim 162$ & $40.3 \pm 0.2$ & \\
\hline$\Delta \mathrm{ZnF}_{755}$ & $\sim 132$ & $36.6 \pm 0.2$ & $7.3 / 3.6$ \\
\hline$\Delta \mathrm{ZnF}_{755}+\mathrm{DNA}$ & $\sim 125$ & $31.8 \pm 0.1$ & $18.1 / 3.9$ \\
\hline Crystal structure of $\Delta$ ZnF-DNA complex & $\sim 103$ & $28.5 \pm 0.2$ & \\
\hline
\end{tabular}

$\mathrm{Rg}$ radius of gyration given by the Guinier approximation (28)

$\mathrm{D}_{\max }$ maximum protein distance estimated from $\mathrm{P}(\mathrm{r})$ function as shown in Figure 3.

$\chi^{2}$ single model /MES, goodness of fit $\chi^{2}$ for best-fit atomic model and multiconformational fit $\chi^{2}$ for MES - models. In $\Delta \mathrm{ZnF} 755+\mathrm{DNA}$ complex, $\chi^{2}$ for single model was calculated from the crystal structure of $\Delta$ ZnF-DNA complex. 